\section{Saúde infantil em áreas pobres das regiões Norte e Nordeste do Brasil: comparando indicadores básicos em áreas atendidas pela Pastoral da Criança e áreas-controle}

\author{
Child health in poor areas of North and Northeast \\ Brazil: a comparison of areas covered \\ by the Children's Mission and control areas
}

1 Departamento MaternoInfantil, Universidade Federal do Rio Grande, Rio Grande, Brasil.

2 Centro de Pesquisas Epidemiológicas, Universidade Federal de Pelotas, Brasil.

3 Secretaria de Assistência

Social, Prefeitura Municipal de Paulo Afonso,

Paulo Afonso, Brasil.

4 Coordenação Nacional,

Pastoral da Criança

Curitiba, Brasil.

Correspondência

J. A. Cesar

Departamento Materno-

Infantil, Universidade

Federal do Rio Grande.

Rua Eng. Alfredo Huch 475,

Rio Grande, RS

96201-900, Brasil.

jacesar@terra.com.br

\section{Abstract}

Community surveys are essential to estimate health indicators, evaluate health programs, and define health interventions. In 2002, a cross sectional survey of children under five was conducted in 18 areas of the poorest counties in North and Northeast Brazil. Nine areas were visited by volunteer community health workers (CHW) under the Children's Mission, and the others were not visited. Using a standard questionnaire, trained interviewers collected information at the household level for 1,528 children, 782 of whom were visited monthly by CHWs and 772 were not. All the children and their families were living below the poverty line; $40.0 \%$ of the parents were illiterate, per capita daily income was about US\$0.30, and household conditions were substandard. However, most were living less than $1 \mathrm{~km}$ from a public health service and almost all children who were referred to these services received medical care. Prenatal care was also poor in terms of number of medical visits and laboratory tests. Children visited by CHWs from the Children's Mission received better care in terms of growth monitoring, number of medical check-ups, and prenatal iron supplementation.

Health Status Indicators; Diagnosis of Health Situation; Program Evaluation; Child Welfare
Juraci A. Cesar 1,2

Tatiane S. Gonçalves 3

Nelson A. Neumann 4

Joel Antônio Oliveira Filho 1,2

Alessandra C. Diziekaniak 1,2

\section{Introdução}

Os diagnósticos comunitários de saúde têm se tornado uma prática freqüente no Brasil 1,2. Eles são essenciais para o conhecimento de indicadores locais de saúde, para a avaliação de programas e para o planejamento e implementação de ações em saúde ${ }^{3}$. Isso tem permitido utilizar recursos em saúde de forma mais racional, oferecer melhores cuidados em saúde e reduzir os índices de morbi-mortalidade, particularmente em relação à saúde materno-infantil 1.

Em geral, esses diagnósticos têm sido realizados em nível estadual ou em municípios que dispõem de boa infra-estrutura em saúde 1,2, mas raramente nas comunidades mais pobres. Em cerca de 37 mil dessas comunidades, atua a Pastoral da Criança, organismo de ação social da Confederação Nacional dos Bispos do Brasil (CNBB). Essa atuação se dá por intermédio de voluntários, moradores da própria comunidade, que recebem capacitação de cerca de 40 horas e tornam-se líderes da Pastoral da Criança (LPC). Essas LPC, geralmente mulheres, oferecem cuidados de conscientização e de educação em saúde e cidadania a não mais que vinte famílias residentes próximas ao seu domicílio ${ }^{4}$. São cerca de 140 mil líderes que visitam mensalmente cerca de 1,25 milhão de famílias, 1,8 milhão de crianças menores de seis anos e 90 mil gestantes em aproximadamente 3.800 municípios nos 27 Estados brasileiros e no Distrito Federal 4. 
O presente estudo teve por objetivo avaliar indicadores básicos de saúde infantil em 18 áreas de alguns dos municípios mais pobres das regiões Norte e Nordeste do Brasil. Esses indicadores foram comparados entre áreas visitadas pelos LPC com áreas de mesmo nível sócio-econômico, mas não visitadas por eles. Os resultados dessa avaliação são apresentados e discutidos a seguir.

\section{Metodologia}

O presente estudo foi realizado em nove dos 32 municípios mais pobres do Brasil, segundo dados do Fundo das Nações Unidas para a Infância e Adolescência (Unicef) e Pastoral da Criança. Os municípios indicados para participar deste estudo foram Macururé (Bahia), Graça e Arneiroz (Ceará), Garrafão do Norte e Santa Cruz do Arari (Pará), Natuba e Mari (Paraíba), Caracol (Piauí) e São Pedro (Rio Grande do Norte). Em cada um deles, foram escolhidas duas áreas, sendo uma delas visitada pelas LPC, e a outra não visitada.

As áreas visitadas pelas LPC (ou áreas-Pastoral) dentro de cada município foram escolhidas através de sorteio aleatório de suas líderes. As áreas não visitadas pelas LPC ou (áreas-nãoPastoral) deveriam ser semelhantes às áreasPastoral em termos de local de residência (urbana ou rural), tipo de moradia (tijolo/bloco, madeira, taipa, papelão), abastecimento de água encanada, rede de esgotos e energia elétrica. Essa área deveria ficar o mais distante possível das áreas-Pastoral a fim de evitar contaminação de ações oferecidas pelos seus LPC.

Optou-se por utilizar um delineamento transversal por ser o mais apropriado para determinar as principais causas de morbidade e de utilização de serviços de saúde em nível populacional em um determinado momento, possibilitar a investigação de múltiplas exposições e desfechos simultaneamente, ser fácil de realizar principalmente por utilizar-se de abordagem única, ser altamente efetivo na avaliação de programas de larga escala e por ser o delineamento mais conveniente para planejar ações em saúde. Além disso, é rápido, fácil de analisar e apresenta baixo custo 3,5 .

Por meio de dois questionários padronizados e previamente testados, coletaram-se informações sobre cada uma dessas crianças e suas famílias. Esses questionários foram aplicados à mãe ou pessoa responsável pela sua guarda no próprio domicílio, por entrevistadores previamente treinados. Um dos questionários buscava informações sobre a família no que diz respeito a características demográficas e nível sócio-econômico dos pais, condições de habitação e saneamento e presença de equipamentos domésticos no domicílio. No outro, buscavam-se informações sobre a criança quanto a características demográficas, assistência à gestação e ao parto, padrão de morbidade prévia e atual, utilização de serviços curativos e preventivos em saúde, idade de introdução de alimentos à dieta infantil, padrão atual de amamentação e dieta e obtenção do peso e altura/comprimento.

Seis entrevistadores graduados em ciências sociais e com experiência neste tipo de estudo foram previamente selecionados e treinados durante cinco dias úteis. O treinamento constou de leitura dos questionários e dos manuais de instrução, simulações de entrevistas e treinamento de antropometria em uma creche. Em seguida, realizou-se estudo piloto visando testar os questionários, familiarizar o entrevistador com a sua aplicação e avaliar a logística da coleta de dados. Depois, todas as dúvidas decorrentes dessa etapa foram discutidas, as alterações pertinentes realizadas e a versão definitiva do questionário impressa.

Dentre os seis entrevistadores treinados, quatro foram selecionados e dois mantidos como suplentes na eventualidade de alguma desistência ou desligamento. A coordenadora do estudo (T.S.G.) já havia sido previamente definida em virtude de sua ampla experiência neste tipo de estudo.

As estimativas para este estudo foram feitas a partir dos seguintes parâmetros: erro alfa de 0,05 , erro beta de 0,20 , precisão (ou erro máximo) 3,9 pontos percentuais, efeito de delineamento de 1,8 , prevalência de exposição variando de $20,0 \%$ a $60,0 \%$ e de desfechos variando de $20,0 \%$ a $80,0 \%$. Isso resultou em "n" (número de crianças) de 1.152. A esse valor foram acrescidos $10,0 \%$ (115 crianças) para possíveis perdas e 15,0\% (190 crianças) para controle de fatores de confusão ${ }^{6}$. Assim, este estudo deveria cobrir, pelo menos, 1.457 crianças menores de cinco anos. Para atingir com segurança esse tamanho de amostra, decidiu-se por incluir 168 crianças por município, sendo 84 provenientes de áreas-Pastoral e 84 de áreas-não-Pastoral, o que totalizaria 1.512 crianças.

Dois sorteios aleatórios foram feitos, sendo um para escolher as crianças atendidas pelas LPC e um outro para aquelas residentes em áreas-não-Pastoral. No caso das crianças atendidas pela Pastoral, as LPC foram listadas em ordem alfabética, e sete delas, aleatoriamente escolhidas. As 12 primeiras crianças constantes no seu caderno foram incluídas no estudo, 
isto é, suas mães foram entrevistadas, e as medidas antropométricas referentes a cada criança, obtidas. Caso a LPC acompanhasse menos de 12 crianças, todas seriam incluídas no estudo. Se não fosse possível completar as 84 (7x12) crianças desejadas por município, outras LPC pertencentes à mesma comunidade seriam sorteadas.

As áreas-não-Pastoral foram escolhidas a partir de informações fornecidas pela própria LPC ou por pessoas da própria comunidade, principalmente líderes comunitários, párocos e vereadores. Esta área indicada era visitada pela coordenadora do estudo, que percorria suas ruas e, em preenchendo os requisitos acima citados, mapeava-as e numerava suas esquinas (ou pontos previamente definidos) em sentido horário, e uma delas era sorteada de forma aleatória. A partir desse ponto e obedecendo à numeração (ou divisão) previamente estabelecida, os entrevistadores visitavam cada um dos domicílios até completar o número desejado de crianças.

A coleta de dados foi realizada em 12 semanas, entre os meses de julho e setembro de 2002, sendo dez semanas destinadas exclusivamente à coleta de dados e duas para retornos dentro do município e para deslocamento entre os municípios. Assim, o trabalho de campo foi completado em cada município em aproximadamente seis dias (50 dias/9 municípios), o que implicou a cada entrevistador realizar, em média, cerca de oito entrevistas por dia (168 crianças por município/5 dias por semana/4 entrevistadores = 8,4 crianças/dia). Ao final de cada dia de trabalho, cada entrevistador revisava os seus questionários e os entregava à coordenadora do estudo para revisão inicial e envio à codificação de questões abertas, revisão final e digitação.

O controle de qualidade dessas entrevistas foi feito pela coordenadora do estudo através de revisão imediata dos questionários e repetição de entrevistas ou de parte delas. As entrevistas repetidas foram escolhidas aleatoriamente ou quando alguma informação parecesse destoante em relação às demais. Cerca de $5,0 \%$ das crianças foram revisitadas, e os questionários parcialmente repetidos para algumas perguntas-chave.

Os dados foram duplamente digitados, e sua consistência inicialmente avaliada utilizando-se do programa Epi Info 6.04. Em seguida, foram obtidas freqüências das variáveis e calculadas as medidas de tendência central e de dispersão. A magnitude da associação entre as diversas variáveis estudadas e o fato de serem ou não visitadas pelos LPC foram avaliados pelo teste do qui-quadrado de Pearson. To- das essas análises foram realizadas utilizandose do programa Stata versão 8.0.

\section{Resultados}

Foram identificadas 1.554 crianças menores de cinco anos nas 18 áreas dos nove municípios estudados. Dessas, obtiveram-se informações sobre 1.528, sendo que $782(51,2 \%)$ pertenciam à área-Pastoral, e 772 (48,8\%), à área-não-Pastoral. Não foi possível obter informações sobre 26 crianças, o que representa $1,7 \%$ de perdas, sendo $11(1,4 \%)$ residentes em área-Pastoral e 16 (2,0\%) em área-não-Pastoral.

O número médio de crianças por município foi 170, variando de 162 (Arneiroz, Ceará) a 180 (Caracol, Piauí). As diferenças inferiores ao número desejado (168 por município) devemse às perdas do estudo, enquanto o excedente decorre de o entrevistador não saber, ao certo, o número de entrevistas realizadas pelos demais e de essa informação não poder ser imediatamente obtida, visto que os entrevistadores trabalhavam separados, e, muitas vezes, um domicílio era bastante distante do outro.

As crianças pertencentes ao grupo Pastoral eram, em média, um mês mais velhas que as do grupo controle (29,5 meses, desvio padrão: 16,2 contra 30,4 meses, desvio padrão: 17,2). Exceto para o primeiro ano de idade, no qual houve um número menor de crianças no grupo Pastoral $(20,3 \%)$ em relação ao grupo não Pastoral (17,9\%); nas demais faixas etárias, essa distribuição foi muito semelhante.

Aproximadamente, 40,0\% das mães e metade dos pais não sabiam ler nem escrever. Cerca de $20,0 \%$ das mães e $15,0 \%$ dos pais não completaram um único ano de escolaridade. Dois terços das famílias dessas crianças possuíam renda familiar inferior a um salário mínimo mensal. Considerando que havia, em média, seis pessoas por domicílio, a renda per capita diária era de $\mathrm{R} \$$ 1,00 (ou US\$ 0,30). A maioria das famílias dessas crianças vivia em casa própria construída predominantemente de tijolos ou blocos, que possuía, em média, quatro cômodos, sendo dois deles utilizados como quarto de dormir. Cerca de 40,0\% dos domicílios não tinham qualquer tipo de sanitário ou privada, mais da metade não recebia água encanada, e somente $15,0 \%$ dos domicílios estavam conectados à rede pública de esgoto. Cerca de um quarto dos domicílios não possuía energia elétrica (Tabela 1).

As crianças residentes em áreas-Pastoral mostraram-se em significativa desvantagem em relação à escolaridade do pai, renda familiar e posse de equipamentos domésticos. 
Tabela 1

Condições sócio-econômicas das famílias de crianças menores de cinco anos residentes em áreas pobres do Norte e do Nordeste do Brasil, 2002.

\begin{tabular}{|c|c|c|c|}
\hline \multirow[t]{2}{*}{ Indicador } & \multicolumn{2}{|c|}{ Área } & \multirow[t]{2}{*}{ Total } \\
\hline & Pastoral & Não-Pastoral & \\
\hline \multicolumn{4}{|l|}{ Sabem ler e escrever } \\
\hline Mães $(p=0,575)$ & $61,9 \%$ & $63,8 \%$ & $62,8 \%$ \\
\hline Pais $(p=0,042)$ & $50,9 \%$ & $57,3 \%$ & $54,1 \%$ \\
\hline \multicolumn{4}{|c|}{ Anos completos de escolaridade da mãe $(p=0,173)$} \\
\hline Nenhum & $21,9 \%$ & $20,2 \%$ & $21,1 \%$ \\
\hline $1-3$ & $36,6 \%$ & $34,5 \%$ & $35,5 \%$ \\
\hline $4-8$ & $34,0 \%$ & $34,7 \%$ & $34,4 \%$ \\
\hline 9 ou mais & $7,5 \%$ & $10,6 \%$ & $9,0 \%$ \\
\hline \multicolumn{4}{|c|}{ Anos completos de escolaridade do pai $(p=0,390)$} \\
\hline Nenhum & $17,0 \%$ & $15,5 \%$ & $16,2 \%$ \\
\hline $1-3$ & $45,3 \%$ & $43,5 \%$ & $44,4 \%$ \\
\hline $4-8$ & $32,8 \%$ & $34,5 \%$ & $33,6 \%$ \\
\hline 9 ou mais & $4,9 \%$ & $6,6 \%$ & $5,8 \%$ \\
\hline \multicolumn{4}{|c|}{ Renda familiar mensal em salários mínimos $(p=0,002)$} \\
\hline Menos de 1 & $68,0 \%$ & $61,6 \%$ & $64,8 \%$ \\
\hline $1-1,9$ & $23,5 \%$ & $24,6 \%$ & $24,0 \%$ \\
\hline 2 ou mais & $8,6 \%$ & $13,9 \%$ & $11,2 \%$ \\
\hline Média em R\$ & 161,70 & 191,90 & 176,60 \\
\hline \multicolumn{4}{|l|}{ Número de moradores por domicílio } \\
\hline Média (desvio padrão) & $6,3(2,7)$ & $6,4(2,6)$ & $6,4(2,7)$ \\
\hline \multicolumn{4}{|l|}{ Se a casa onde mora é $(p=0,817)$} \\
\hline Própria & $70,3 \%$ & $68,8 \%$ & $69,6 \%$ \\
\hline Alugada & $9,1 \%$ & $9,4 \%$ & $9,2 \%$ \\
\hline Emprestada & $20,6 \%$ & $21,8 \%$ & $21,2 \%$ \\
\hline \multicolumn{4}{|l|}{ Tipo de construção da moradia $(p=0,238)$} \\
\hline Tijolo/Bloco & $60,3 \%$ & $64,0 \%$ & $62,1 \%$ \\
\hline Taipa & $24,5 \%$ & $21,0 \%$ & $22,8 \%$ \\
\hline Madeira & $15,1 \%$ & $15,0 \%$ & $15,1 \%$ \\
\hline \multicolumn{4}{|l|}{ Número de compartimentos } \\
\hline No domicílio (média e desvio padrão) & $4,3(1,7)$ & $4,4(1,8)$ & $4,3(1,7)$ \\
\hline Para dormir (média e desvio padrão) & $1,9(0,9)$ & $2,0(0,9)$ & $2,0(0,9)$ \\
\hline \multicolumn{4}{|l|}{ Não possuem no domicílio } \\
\hline Qualquer tipo de sanitário $(p=0,636)$ & $39,0 \%$ & $40,2 \%$ & $39,6 \%$ \\
\hline Água encanada $(p=0,960)$ & $54,0 \%$ & $53,4 \%$ & $53,7 \%$ \\
\hline Rede de esgoto $(p=0,246)$ & $86,4 \%$ & $84,3 \%$ & $85,3 \%$ \\
\hline Energia elétrica $(p=0,249)$ & $23,3 \%$ & $24,7 \%$ & $24,2 \%$ \\
\hline Total $(\mathrm{N}=1.528)$ & $100,0 \%$ & $100,0 \%$ & $100,0 \%$ \\
\hline
\end{tabular}


Aproximadamente, dois terços dos domicílios dispunham de rádio; pouco mais da metade, televisão, e somente em um quarto delas havia geladeira. Filtro de água foi identificado em pouco menos de 30,0\% dos domicílios, e fogão a gás e/ou a lenha, em cerca de três quartos deles. A Tabela 2 mostra esses dados.

A Tabela 2 revela que menos de um quinto das famílias possuía colher-medida, e essa posse foi comprovada. Cerca de um terço dessas famílias nunca teve uma colher-medida para preparar soro reidratante oral em qualquer momento no passado. Entre todas as famílias, a forma mais comum de obter colher-medida foi por intermédio do agente comunitário de saúde $(42,0 \%)$, seguido pelo LPC $(27,0 \%)$.

Famílias visitadas pelas LPC estiveram em nítida vantagem em relação à posse de colheres-medida no momento da entrevista e no passado e moravam mais próximas aos serviços de saúde, enquanto as famílias não atendidas pela pastoral residiam mais próximas de hospitais e prontos-socorros, serviços de maior complexidade.

A Tabela 3 mostra que, para cerca de três quartos das famílias, os postos de saúde eram os serviços de saúde mais próximos de suas residências. Cerca de dois terços das crianças estudadas residiam a menos de $1 \mathrm{~km}$ desse serviço de saúde.

A Tabela 3 mostra que aproximadamente 85,0\% das mães dessas crianças fizeram, pelo menos, uma consulta de pré-natal, dois terços das quais iniciaram ainda no primeiro trimestre de gravidez. No entanto, pouco mais de $40,0 \%$ delas realizaram seis ou mais consultas durante toda a gestação, e pouco mais da metade de todas as gestantes recebeu três doses de vacina antitetânica. Os exames laboratoriais mais comumente realizados durante o pré-natal foram o de fezes, urina e ultra-sonografia, enquanto os menos realizados foram para detecção de sífilis e hepatite. A pressão arterial e a ausculta cardíaca fetal foram os exames clínicos mais freqüentemente referidos como sendo realizados durante essas consultas. Somente 7,0\% das mães dessas crianças foram pesadas em algum momento do pré-natal. Cerca de $80,0 \%$ delas receberam sulfato ferroso durante a gravidez e tiveram seus bebês em maternidade ou hospital. Quase 90,0\% dessas crianças nasceram de parto normal, mas somente $41,0 \%$

Disponibilidade de eletrodomésticos, posse de colheres-medida e local de obtenção para crianças menores de cinco anos residentes em áreas pobres do Norte e do Nordeste do Brasil, 2002.

\begin{tabular}{|c|c|c|c|}
\hline \multirow[t]{2}{*}{ Indicador } & \multicolumn{2}{|c|}{ Área } & \multirow[t]{2}{*}{ Total (\%) } \\
\hline & Pastoral (\%) & Não-Pastoral (\%) & \\
\hline \multicolumn{4}{|l|}{ Equipamentos domésticos } \\
\hline Rádio $(p=0,028)$ & 61,9 & 67,2 & 64,5 \\
\hline Televisão ( $p=0,384)$ & 55,2 & 57,5 & 56,3 \\
\hline Geladeira $(p=0,031)$ & 22,6 & 27,3 & 24,9 \\
\hline Filtro $(p=0,907)$ & 28,3 & 28,0 & 28,1 \\
\hline Fogão a gás $(p=0,012)$ & 71,1 & 76,7 & 73,9 \\
\hline Fogão a lenha/carvão $(p=0,004)$ & 75,9 & 69,3 & 72,6 \\
\hline \multicolumn{4}{|l|}{ Posse da colher-medida $(p=0,000)$} \\
\hline Tinha e foi vista & 25,2 & 11,9 & 18,6 \\
\hline Tinha, mas não foi vista & 16,7 & 11,8 & 14,3 \\
\hline Tinha, mas perdeu & 33,1 & 40,2 & 36,6 \\
\hline Nunca teve & 25,0 & 36,2 & 30,6 \\
\hline \multicolumn{4}{|c|}{ Onde conseguiu esta colher-medida $(p=0,000)$} \\
\hline Posto de saúde & 11,6 & 22,2 & 16,4 \\
\hline Com o agente de saúde & 31,8 & 54,3 & 42,1 \\
\hline Com o líder da Pastoral & 47,0 & 3,5 & 27,1 \\
\hline Outros & 9,6 & 20,0 & 14,4 \\
\hline Total $(\mathrm{N}=1.528)$ & 100,0 & 100,0 & 100,0 \\
\hline
\end{tabular}


Características dos serviços de saúde e assistência à gestação e ao parto para crianças menores de cinco anos residentes em áreas pobres do Norte e do Nordeste do Brasil, 2002.

\begin{tabular}{|c|c|c|c|}
\hline \multirow[t]{2}{*}{ Indicador } & \multicolumn{2}{|c|}{ Área } & \multirow[t]{2}{*}{ Total $(\%)$} \\
\hline & Pastoral (\%) & Não-Pastoral (\%) & \\
\hline \multicolumn{4}{|l|}{ Serviço de saúde mais próximo do domicílio $(p=0,001)$} \\
\hline Posto de saúde & 76,5 & 76,3 & 76,4 \\
\hline Atendimento 24 horas & 21,9 & 18,8 & 20,3 \\
\hline Hospital/Pronto-socorro & 1,6 & 4,9 & 3,2 \\
\hline \multicolumn{4}{|l|}{ Distância (em km) a este serviço de saúde $(p=0,001)$} \\
\hline $0-0,9$ & 64,8 & 57,9 & 61,3 \\
\hline $1-4,9$ & 18,6 & 15,1 & 16,8 \\
\hline 5 ou mais & 16,5 & 27,0 & 21,8 \\
\hline Fizeram pré-natal $(p=0,478)$ & 86,6 & 85,4 & 86,0 \\
\hline $\begin{array}{l}\text { Iniciaram o pré-natal no primeiro trimestre } \\
(p=0,221)(N=1.480)\end{array}$ & 69,6 & 65,8 & 67,8 \\
\hline $\begin{array}{l}\text { Realizaram seis ou mais consultas de pré-natal } \\
(p=0,006)(N=1.480)\end{array}$ & 45,2 & 38,2 & 41,8 \\
\hline $\begin{array}{l}\text { Imunização completa contra tétano neonatal } \\
(p=0,048)(N=1.457)\end{array}$ & 51,7 & 56,9 & 54,3 \\
\hline \multicolumn{4}{|l|}{ Exames laboratoriais realizados $(\mathrm{N}=1.480)$ : } \\
\hline Fezes e urina $(p=0,378)$ & 54,2 & 54,2 & 54,2 \\
\hline Ultra-sonografia $(p=0,089)$ & 41,5 & 46,3 & 43,8 \\
\hline Citopatológico de colo uterino $(p=0,174)$ & 12,4 & 12,3 & 12,3 \\
\hline $\operatorname{HIV}(p=0,746)$ & 7,8 & 8,3 & 8,0 \\
\hline $\operatorname{VDRL}(p=0,528)$ & 7,2 & 8,1 & 7,6 \\
\hline Hepatite $(p=0,133)$ & 6,1 & 8,3 & 7,2 \\
\hline \multicolumn{4}{|l|}{ Exames clínicos realizados $(N=1.480)$ : } \\
\hline Pressão arterial $(p=0,599)$ & 92,8 & 92,0 & 92,4 \\
\hline Ausculta cardíaca fetal $(p=0,565)$ & 84,7 & 85,6 & 85,3 \\
\hline Altura uterina $(p=0,373)$ & 55,6 & 53,1 & 54,4 \\
\hline Edema de membros inferiores $(p=0,297)$ & 66,1 & 63,3 & 35,2 \\
\hline Pesagem $(p=0,133)$ & 6,1 & 8,3 & 7,2 \\
\hline Receberam sulfato ferroso $(p=0,011)$ & 84,0 & 78,4 & 81,3 \\
\hline Nasceram em hospital ou maternidade $(p=0,547)$ & 81,0 & 79,8 & 80,4 \\
\hline Nasceram de parto normal $(p=0,112)(N=1.528)$ & 88,2 & 85,4 & 86,8 \\
\hline Nasceram com peso inferior a $2.500 \mathrm{~g}(p=0,649)$ & 7,8 & 8,5 & 8,2 \\
\hline Total $(\mathrm{N}=1.528)$ & 100,0 & 100,0 & 100,0 \\
\hline
\end{tabular}

de todos os partos foram assistidos por médicos. Finalmente, $8,0 \%$ dos nascimentos tiveram peso inferior a 2.500 gramas, e somente $18,0 \%$ de todas as mães fizeram revisão no puerpério (Tabela 3). As informações sobre pré-natal aqui referidas dizem respeito a todas as crianças menores de cinco anos existentes no domicílio visitado.

Um maior número de mães pertencentes às áreas-Pastoral realizaram seis ou mais consul- tas de pré-natal e receberam mais freqüentemente suplementação de sulfato ferroso no período gestacional.

Uma em cada seis crianças havia sido hospitalizada nos 12 meses antecedentes à entrevista (Tabela 4). As infecções respiratórias e as doenças diarréicas responderam por quase $70,0 \%$ dessas internações. Pouco mais de 40,0\% dessas crianças foram levadas à consulta nos serviços de saúde nos três meses anteriores à 
Padrão de morbidade e de utilização de serviços curativos e preventivos de saúde para crianças menores de cinco anos residentes em áreas pobres do Norte e do Nordeste do Brasil, 2002.

\begin{tabular}{|c|c|c|c|}
\hline \multirow[t]{2}{*}{ Indicador } & \multicolumn{2}{|c|}{ Área } & \multirow{2}{*}{ Total $(\%)$} \\
\hline & Pastoral (\%) & Não-Pastoral (\%) & \\
\hline Hospitalizações nos últimos 12 meses ( $p=0,548)$ & 14,3 & 13,2 & 13,7 \\
\hline \multicolumn{4}{|l|}{ Principais causas } \\
\hline Infecção respiratória baixa $(p=0,485)$ & 5,2 & 5,0 & 5,1 \\
\hline Diarréia $(p=0,811)$ & 4,8 & 3,6 & 4,2 \\
\hline Outras $(p=0,865)$ & 4,3 & 4,6 & 4,4 \\
\hline Realizaram consulta médica nos últimos três meses $(p=0,665)$ & 41,1 & 40,0 & 40,6 \\
\hline Com médico $(p=0,484)$ & 35,1 & 34,9 & 35,0 \\
\hline Com enfermeiro $(p=0,677)$ & 6,7 & 6,1 & 6,4 \\
\hline Estiveram doentes nos últimos 14 dias $(p=0,311)$ & 30,1 & 32,5 & 31,3 \\
\hline \multicolumn{4}{|l|}{ Doenças/Sintomas ocorridos nos últimos 15 dias } \\
\hline Infecção respiratória aguda alta $(p=0,622)$ & 53,9 & 51,6 & 52,7 \\
\hline Diarréia/Disenteria $(p=0,651)$ & 20,3 & 21,9 & 21,1 \\
\hline Doenças de pele/Impetigo $(p=0,591)$ & 9,5 & 11,0 & 10,2 \\
\hline Dispnéia $(p=0,357)$ & 7,3 & 5,3 & 6,3 \\
\hline Taquipnéia ( $p=0,567)$ & 3,4 & 4,5 & 4,0 \\
\hline Foram levadas ao serviço de saúde $(p=0,983)(N=463)$ & 48,2 & 48,1 & 48,2 \\
\hline Conseguiram atendimento $(p=0,068)(N=222)$ & 99,1 & 94,8 & 96,8 \\
\hline $\begin{array}{l}\text { Crianças que receberam soro reidratante oral durante } \\
\text { os episódios de diarréia nos últimos } 15 \text { dias }(p=0,673)(N=101)\end{array}$ & 69,6 & 70,4 & 69,8 \\
\hline \multicolumn{4}{|l|}{ Prevalência de déficit nutricional $\leq-2$ desvios padrão $(N=1.486)$} \\
\hline Altura/ldade $(p=0,073)$ & 16,6 & 14,6 & 15,6 \\
\hline Peso/ldade $(p=0,016)$ & 8,5 & 7,0 & 7,8 \\
\hline Peso/Altura $(p=0,103)$ & 1,7 & 2,2 & 1,9 \\
\hline $\begin{array}{l}\text { Prevalência de sobrepeso e obesidade } \\
(\geq+2 \text { desvios padrão) }(p=0,070)(N=1.485)\end{array}$ & 3,6 & 3,5 & 3,6 \\
\hline $\begin{array}{l}\text { Recebimento comprovado de vitamina A nos últimos } \\
\text { seis meses* }(p=0,789)(N=1.393)\end{array}$ & 54,4 & 52,8 & 53,6 \\
\hline Posse comprovada do cartão da criança $(p=0,002)$ & 94,3 & 86,8 & 90,6 \\
\hline $\begin{array}{l}\text { Foram pesadas nas últimas quatro semanas }{ }^{\star \star} \\
(p=0,000)(N=593)\end{array}$ & 78,3 & 62,3 & 70,7 \\
\hline $\begin{array}{l}\text { Receberam esquema vacinal básico completo ( } 3 \text { doses de Sabin } \\
\text { e DPT e } 1 \text { dose de anti-sarampo e BCG })^{\star \star \star}(p=0,000)(N=1.199)\end{array}$ & 89,8 & 82,2 & 86,1 \\
\hline Total $(\mathrm{N}=1.528)$ & 100,0 & 100,0 & 100,0 \\
\hline
\end{tabular}

* somente para crianças com seis meses ou mais de idade; ** somente para crianças menores de dois anos;

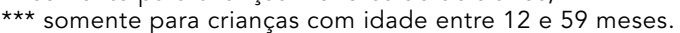


entrevista. Somente $15,0 \%$ dessas consultas foram realizadas com enfermeiras, enquanto as demais, com médicos. As infecções respiratórias responderam sozinhas por mais da metade dessas consultas $(53,0 \%)$, seguido pelas doenças diarréicas $(21,0 \%)$ e doenças de pele $(10,0 \%)$.

Cerca de um terço de todas as crianças estiveram doentes nas duas semanas que antecederam à entrevista. Dessas, quase metade delas foi levada à consulta médica, com praticamente todas $(97,0 \%)$ conseguindo atendimento médico no serviço público de saúde. Dentre as crianças que tiveram diarréia em ambas as áreas, cerca de $70,0 \%$ receberam soro reidratante oral durante os episódios. A prevalência de déficit moderado ou grave $(\leq 2$ desvios padrão) para o indicador altura/idade foi de aproximadamente $15,0 \%$, cerca de duas vezes maior que o déficit peso/idade $(7,8 \%)$ e oito vezes maior que o déficit peso/altura (1,9\%) A prevalência de sobrepeso e obesidade $(\geq+2$ desvios padrão) $(3,5 \%)$ foi quase duas vezes maior que o déficit de peso para altura (Tabela 4 ).

A Tabela 4 mostra ainda dados referentes à cobertura de serviços preventivos nessas áreas. Pouco mais de metade das crianças com idade entre 6 e 59 meses recebeu vitamina A nos seis meses antecedentes à entrevista; cerca de 90,0\% de todos os menores de cinco anos possuíam cartão da criança, 70,0\% dos menores de dois anos haviam sido pesados nas últimas quatro semanas, e 86,0\% daqueles com idade entre 12 e 59 meses haviam recebido o esquema vacinal básico completo (três doses de Sabin e DPT e uma dose de anti-sarampo e BCG).

Em relação ao padrão de morbidade e de utilização de serviços curativos em saúde, não houve diferença estatisticamente significativa entre crianças de ambas as áreas.

A Tabela 5 traz um resumo de variáveis e indicadores avaliados que mostraram diferenças estatisticamente significativas entre as áreas estudadas. No geral, crianças residentes em área-Pastoral possuíam pior nível sócio-econômico, mas apresentavam melhor cobertura para a maioria dos serviços preventivos em saúde, principalmente aqueles rotineiramente oferecidos pela LPC durante suas visitas.

\section{Discussão}

A maioria das crianças estudadas sobrevive em um ambiente de extrema pobreza. O nível de escolaridade dos seus pais é muito baixo, sua renda familiar insuficiente ao suprimento de necessidades básicas como alimentação, por exemplo; o número de moradores por domicí- lio mostrou-se demasiadamente alto, as condições de habitação e saneamento bastante impróprias; os cuidados de pré-natal recebidos foram inadequados em termos quantitativos e principalmente qualitativos; doenças potencialmente letais nos primeiros anos de vida, como diarréia e infecções respiratórias baixas, mostraram-se endêmicas nas áreas estudadas. No entanto, a maioria das famílias vive muito próxima a algum serviço público de saúde que, via de regra, atende todas as crianças que lhe são encaminhadas. Em relação à comparabilidade entre as áreas, verificou-se que, apesar de as crianças residentes em áreas-Pastoral apresentarem pior nível sócio-econômico, vários indicadores de utilização de serviços preventivos mostraram-se consistentemente melhores que os observados nas áreas não visitadas pelos LPC. Isso pode ser, em parte, decorrente da maior proximidade destes aos serviços de saúde.

Ao se interpretar esses achados, é preciso ter em mente algumas limitações comuns a este tipo de estudo e como foram aqui contornadas. Neste tipo de delineamento, (1) exposição e efeito são medidos em um mesmo momento, o que dificulta estabelecer relação de causalidade, (2) estudos transversais são pouco adequados para estudar doenças de muito curta ou longa duração, o que pode levar a estimativa incorreta dos achados, (3) pouco apropriado para investigar doenças raras por requerer um tamanho de amostra muito grande, o que demandaria elevado custo e longos períodos de coleta de dados, e (4) mostrar-se pouco adequado na investigação de eventos no passado, o que acarretaria em viés de memória 5,7 . Nenhuma dessas limitações parece ter afetado este estudo pelas seguintes razões: (1) a relação temporal dos eventos em observação já foi claramente determinada por outros delineamentos, principalmente os longitudinais que medem exposição e doença em momentos distintos, (2) nenhuma das condições a serem aqui abordadas são consideradas de tão curta duração a ponto de subestimar os resultados ou tão longo a ponto de superestimá-los, e (3) os eventos em estudo são de ocorrência freqüente, e (4) quanto ao viés de memória, isso pode ter ocorrido, por exemplo, com as informações referentes ao pré-natal 5,7,8. Nesse caso, mães que tiveram filho recentemente lembraram com mais facilidade dos cuidados recebidos durante o pré-natal do que aquelas mães que tiveram filho há mais tempo, visto que algumas crianças possuíam até cinco anos de idade. No entanto, se isso de fato ocorreu, afetou os dois grupos, visto que as crianças estudadas pertenciam à mesma faixa etária. Ainda, as crianças 
Resumo da comparabilidade das variáveis com diferenças estatisticamente significativas entre áreas

visitadas pelos líderes da Pastoral (áreas-Pastoral) e áreas não visitadas (áreas-não-Pastoral) nas regiões

Norte e do Nordeste do Brasil, 2002.

\begin{tabular}{lc}
\hline Indicador & $\begin{array}{c}\text { Área em vantagem } \\
\text { Não-Pastoral }\end{array}$ \\
\hline Escolaridade dos pais & $\checkmark$ \\
Renda familiar & $\checkmark$ \\
Posse de eletrodomésticos & $\checkmark$ \\
Posse da colher-medida para preparar soro reidratante & $\checkmark$ \\
Distância ao serviço de saúde & $\checkmark$ \\
Realizaram seis ou mais consultas durante o pré-natal & $\checkmark$ \\
Receberam suplementação com sulfato ferroso & $\checkmark$ \\
Posse do cartão de saúde da criança & $\checkmark$ \\
Monitoração do crescimento nas últimas quatro semanas para crianças \\
menores de dois anos de idade \\
Cobertura vacinal básica
\end{tabular}

das áreas-Pastoral eram, em média, um mês mais velhas que as crianças das áreas-não-Pastoral. Isso decorre do fato de a Pastoral ter dificuldade em recrutar a criança nas primeiras semanas após o nascimento e também de, neste estudo, ter-se escolhido as primeiras 12 crianças constantes no caderno da líder, que, via de regra, são mais velhas. No entanto, isso não parece ter afetado de forma importante esses resultados, porque pouquíssimas líderes sorteadas acompanhavam mais de 12 crianças. Finalmente, o fato de a amostragem ter sido por conglomerados e de esses apresentarem número diferente de crianças poder superestimar o grau de associação entre variáveis deve ser levado em conta, sobretudo ao comparar-se os resultados aqui obtidos com o de outros estudos.

Este estudo foi realizado em uma das áreas mais pobres do interior do Brasil. Dessa pobreza quase que absoluta advém o elevado padrão de morbidade entre as crianças estudadas. No entanto, chama a atenção o fato de mais de $60,0 \%$ de todas as crianças residirem a menos de $1 \mathrm{~km}$ de algum serviço público de saúde e de praticamente todas aquelas encaminhadas a esses serviços terem conseguido atendimento médico. Isso sugere que o acesso geográfico a cuidados em saúde, mesmo nessas áreas, é bom, o que parece ser resultado da expressiva expansão do Programa Saúde da Família (PSF) em curso no país desde meados de 1990 9. No entanto, a qualidade dos serviços oferecidos é ainda inadequada. O pré-natal dessas crianças mostra isso claramente. Um expressivo percentual de mães não fez o número mínimo reco- mendado de consultas, não foi submetida a exames laboratoriais e clínicos básicos durante a gestação e também não foi adequadamente imunizada contra tétano neonatal. Isso sugere que essa expansão dos serviços de saúde não está sendo acompanhada de melhoria na sua qualidade. Isso foi também recentemente identificado em Sergipe. Naquele Estado, o pré-natal mostrou-se insuficiente em termos quantitativos e, impróprio em termos qualitativos. Além disso, o manejo de doenças comuns na infância também foi muito pouco adequado. Por exemplo, embora a maioria das crianças sergipanas tenha sido acometida por doenças autolimitadas nos últimos 15 dias, cerca de $95,0 \%$ delas receberam algum medicamento durante consulta médica, dois terços dos quais eram antibióticos 10. O uso abusivo de medicamentos expõe a criança a riscos desnecessários, induz a criação de cepas resistentes, aumenta o custo do programa e diminui a sua efetividade 11 .

Crianças visitadas pelas LPC apresentavam nítida vantagem quanto à posse atual e no passado de colheres-medida. Essas colheres praticamente inexistiam nos serviços formais de saúde das áreas estudadas, que preferiam trabalhar com o soro de pacote. Os poucos agentes comunitários que ainda distribuíam colheres-medida o faziam porque também atuavam como líderes da pastoral. Ao que se percebe, a distribuição de colheres-medida está se tornando uma atividade quase que exclusiva da Pastoral da Criança. Considerando a baixa cobertura da Pastoral da Criança em nível nacio- 
nal, cerca de $22,0 \% 4$, é possível supor que a doença diarréica não esteja sendo adequadamente manejada em muitas crianças, visto que poucas possuem colheres-medida, e o soro de pacote esteja faltando em muitas dessas áreas. Além disso, cerca de 30,0\% das crianças de ambas as áreas não receberam soro reidratante oral durante os episódios da doença.

Nos últimos anos, a Pastoral da Criança tem intensificado o recrutamento de gestantes. $\mathrm{Pa}$ ra isso, lançou algumas estratégias, tais como a do Laços de Amor, que consiste em ensinar a gestante sobre cada um dos cuidados a que tem direito durante a consulta médica e sobre a sua utilidade. Há ainda as Rodas de Conversa que têm por objetivo discutir, em pequenas reuniões, temas de interesse da comunidade, particularmente das mulheres. Nessas situações, temas, como o pré-natal, são discutidos (http://www.pastoraldacrianca.org.br, acessado em 28/Jul/2004). É bem possível que essas estratégias possam levar mais gestantes ao prénatal e que isso possa ajudar a explicar este melhor desempenho da Pastoral em relação ao maior número de consultas realizadas e suplementação com sulfato ferroso nesse período. No entanto, não há ainda nenhum estudo mostrando a efetividade dessas iniciativas.

A monitoração do crescimento é a porta de entrada dos profissionais de saúde nos domicílios, particularmente dos agentes comunitários de saúde e dos líderes da Pastoral da Criança. Essa atividade é tão importante para os líderes a ponto de transformá-la no Dia da Celebração da Vida, um dia de encontro comunitário. Nesse dia, as crianças são pesadas, estimuladas a brincar, ganham um lanche, e, às vezes, suas mães recebem ensinamentos sobre diversos temas, tais como amamentação e dieta infantil. O enorme investimento feito na monitoração do crescimento pela Pastoral da Criança e a intensa participação das mães e crianças pare- cem justificar os resultados observados. No entanto, essa pesagem, às vezes quase que excessiva, não tem se mostrado capaz de contribuir para melhoras significativas das condições de saúde infantil em programas de larga escala 12.

A cobertura vacinal básica é boa em todo o país, inclusive nas áreas mais pobres como as aqui apresentadas. A instituição do Dia Nacional de Imunização, no início dos anos 80, foi fundamental para que isso ocorresse. $O$ freqüente contato entre as líderes da pastoral e as mães, ocasião em que também recomendam a imunização de menores de cinco anos, pode ser considerado um dos fatores determinantes na maior cobertura observada nas áreas-Pastoral. Isso já havia sido identificado em dois outros estudos que avaliaram indicadores de saúde em áreas atendidas em relação às áreas nãoatendidas pelos LPC 13,14.

Este artigo denuncia a miserabilidade em que sobrevivem essas crianças e suas famílias. A renda per capita de $\mathrm{R} \$ 1,00$ equivale a menos de um terço do que se denomina linha de pobreza. Logo, se fossem pobres, estariam em situação substancialmente melhor. Nessas mesmas áreas de quase total indigência, verificouse que se chega ao serviço público de saúde com relativa facilidade e que, quando isso ocorre, a criança recebe algum atendimento médico. No entanto, a qualidade dos cuidados oferecidos é bastante inadequada.

Finalmente, a vantagem observada para alguns indicadores nas áreas-Pastoral não foi, pelo menos aparentemente, suficiente para melhorar, de forma expressiva, as condições de saúde e nutrição dessas crianças. Por essa razão, intervenções específicas baseadas nos resultados aqui apresentados estão sendo implementadas nessas comunidades e serão posteriormente avaliadas a fim de medir o possível impacto sobre a saúde materno-infantil das visitas realizadas pelos LPC. 


\section{Resumo}

Os diagnósticos comunitários de saúde são essenciais para o conhecimento de indicadores locais de saúde, avaliação de programas e implementação de ações em saúde. Em meados de 2002, realizou-se diagnóstico de saúde infantil em 18 áreas de nove municípios pobres nas regióes Norte e Nordeste do Brasil. Nove dessas áreas eram visitadas pelos líderes da Pastoral da Criança (LPC) e as outras não. Por meio de questionários padronizados, entrevistadores previamente treinados coletaram informações no domicílio sobre 1.528 crianças menores de cinco anos, sendo 782 visitadas pelas LPC e 772 não visitadas. Essas crianças e suas famílias viviam em situação de extrema pobreza; 40,0\% dos seus pais não eram alfabetizados, a renda per capita diária era de US\$0,30, as condições de moradia, muito ruins. No entanto, a maioria dessas crianças vivia a menos de $1 \mathrm{~km}$ de algum serviço público de saúde, e praticamente todas aquelas levadas à consulta médica conseguiram atendimento. O pré-natal foi inadequado em termos quantitativos e qualitativos. Crianças visitadas pelas LPC apresentaram melhor monitoração do crescimento, suas mães fizeram mais consultas de pré-natal e receberam mais freqüentemente sulfato ferroso.

Indicadores de Saúde; Diagnóstico da Situação em Saúde; Avaliação de Programas; Bem-estar da Criança

\section{Colaboradores}

J. A. Cesar delineou o estudo, preparou o questionário, analisou os dados e redigiu o artigo; T. S. Gonçalves treinou os entrevistadores, fez o estudo piloto, supervisionou o trabalho de campo, fez o controle de qualidade e auxiliou na análise e redação do artigo; N. A. Neumann auxiliou no delineamento, análise de dados e redação do artigo; J. A. Oliveira Filho realizou a digitação, comparou os dados, corrigiu a digitação e auxiliou na análise de dados; A. C. Diziekaniak revisou a codificação dos questionários e auxiliou na redação do artigo.

\section{Agradecimentos}

À Pastoral da Criança, organismo de ação social da Confederação Nacional dos Bispos do Brasil (CNBB), ao Fundo das Nações Unidas para Infância e Adolescência (Unicef), ao Programa Criança Esperança da Rede Globo de Televisão, às prefeituras municipais de Macururé (Bahia), Graça e Arneiroz (Ceará), Garrafão do Norte e Santa Cruz do Arari (Pará), Natuba e Mari (Paraíba), Caracol (Piauí) e São Pedro (Rio Grande do Norte) e, finalmente, às mães, crianças e coordenadores e líderes da Pastoral da Criança nesses estados e municípios.

\section{Referências}

1. Cufino-Svitone E, Garfield R, Vasconcelos MI, Araujo-Craveiro V. Primary health care lessons from the northeast of Brazil: the Agentes de Saude Program. Rev Panam Salud Pública 2000; 7 (5 Suppl):293-302.

2. Cesar JA, Horta BH. Desigualdade e perversidade: a dimensão do adoecer no extremo Sul do Brasil. Rio Grande: Editora da Fundação Universidade Federal do Rio Grande; 1996.

3. Ross DA, Vaughan JP. Health interview surveys in developing countries: a methodological review. Stud Fam Plann 1986; 2:78-94.

4. Sistema de Informação da Pastoral da Criança. Relatório extrato indicadores. Abrangência por níveis. Brasil, 2004. http://www.pastoraldacrianca.org.br/pastai-dev (acessado em 07/Jun/2005).

5. Kelsey JL, Whittemore AS, Evans AS, Thompson WD. Methods in observational epidemiology. New York: Oxford University Press; 1994.

6. Smith PG, Day NE. The design of case-control studies: the influence of confounding and interactions effects. Int J Epidemiol 1984, 3:356-65.

7. Silva IS. Cancer epidemiology: principles and methods. Lyon: World Health Organization/International Agency for Research on Cancer; 1999.

8. Victora CG, Barros FC, Vaughan JP. Epidemiologia da desigualdade: um estudo longitudinal de 6.000 crianças brasileiras. 2a Ed. São Paulo: Editora Hucitec; 1988.
9. Coordenação de Saúde Comunitária/Programa de Agentes Comunitários de Saúde. Programa de agentes comunitários de saúde. Brasília: Ministério da Saúde; 2003.

10. Cesar JA. Community health workers in Sergipe, Brazil: implications for their future in maternal and child health [Tese de Doutorado]. London: London School of Hygiene and Tropical Medicine, London University; 2005.

11. Lieberman JM. Appropriate antibiotic use and why it is important: the challenges of bacterial resistance. Pediatr Infect Dis J 2003; 22:1143-51.

12. Save the Children. Thin on the ground: questioning the evidence behind World Bank-funded community nutrition projects in Bangladesh, Ethiopia and Uganda. London: Save the Children; 2003.

13. Victora CG, Barros FC, Cesar JA, Horta BL, Lima SM. A Pastoral da Criança e a saúde materno-infantil em dois municípios do Maranhão. Brasília: Fundo das Nações Unidas para a Infância; 1991.

14. Neumann NA, Victora CG, Halpern R, Guimarães PRV, Cesar JA. Desempenho da Pastoral da Criança na promoção de ações de sobrevivência infantil e na educação em saúde em Criciúma, uma cidade do Sul do Brasil. Rev Panam Salud Pública 1999; 5 (6 Suppl):400-10.

Recebido em 20/Ago/2004

Versão final reapresentada em 03/Mai/2005

Aprovado em 24/Mai/2005 